\title{
VESTÍGIOS “DOS JOVENS ANOS ESCOLARES” DE UMA INTELECTUAL BRASILEIRA: ITINERÁRIOS DA ALUNA MARIA THETIS NUNES NO ATHENEU SERGIPENSE (1935-1941)
}

\author{
João Paulo Gama Oliveira1
}

\begin{abstract}
Resumo: Maria Thetis Nunes (1923-2009) constitui-se como uma intelectual brasileira que atuou em diferentes áreas do conhecimento ao longo do século XX. Nascida na cidade sergipana de Itabaiana, a jovem deixou o interior para prosseguir os estudos na capital Aracaju. Ali, no Atheneu Sergipense, cursou o ensino secundário entre 1935 e 1941. No ano seguinte ingressou na primeira turma da graduação em Geografia e História da Faculdade de Filosofia da Bahia. Nesse sentido, os seus itinerários como aluna do ensino secundário é o foco da presente pesquisa que possui como fontes: atas, jornais, discursos e depoimentos em diálogo com o referencial teórico de Jean-François Sirinelli $(1998,2003,2006)$. O estudo concluiu que "professoresparadigma" são creditados como influenciadores dos caminhos percorridos pela jovem estudante secundarista. As práticas escolares dos seus professores, somadas ao universo cultural no qual Thetis Nunes esteve imersa - contando com contribuições do ambiente familiar e com as amizades dentro e fora da sala de aula, participando de agremiações estudantis e publicando na imprensa local ainda na condição de discente - reafirmam a importância dos estudos dos itinerários formativos para a compreensão da intelectual, bem como da História da Educação brasileira.
\end{abstract}

Palavras-chave: Atheneu Sergipense; Intelectual; Itinerários; Maria Thetis Nunes.

\section{THE REMAINS “OF YOUNG SCHOLAR YEARS” OF A BRAZILIAN INTELECTUAL: ITINERARY OF THE STUDENT MARIA THETIS NUNES AT ATHENEU SERGIPENSE (1935-1941)}

\begin{abstract}
Maria Thetis Nunes (1923-2009) was a Brazilian intellectual that acted in different knowledge areas during the $20^{\text {th }}$ century. Born in the city from Sergipe, Itabaiana, the young woman left the inland city to continue her studies in the capital city Aracaju. There, at Atheneu Sergipense, she studied the high school between 1935 and 1941. In the next year, she entered at the first graduation class in Geography and History of the Philosophy College of Bahia. In that matter, her itinerary as student of high school was the focus the present research that has as source: records, papers,
\end{abstract}

1 Doutor em Educação pela Universidade Federal do Sergipe (Brasil). Contato: jpg oliveira@yahoo.com.br. 
speeches and testimonies in dialogs with the theoretical reference of Jean-François Sirinelli $(1998,2003,2006)$. The study concluded that "paradigm-teachers" are credited as influences of paths went through the young high school student. The scholar practices of her teachers, added to the cultural universe in which Thetis Nunes was immersed, counting with the familiar environment contribution, with the friendships inside and outside the classroom, the participation in student organizations and publishing at the local press still as student, reaffirms the importance of the formation itinerary to the intellectual comprehension, as well as, of the Brazilian education history.

Keywords: Atheneu Sergipense. Intellectual. Itinerary. Maria Thetis Nunes.

Maria Thetis Nunes (1923-2009) constitui-se como uma intelectual brasileira nascida no seio de família humilde na cidade sergipana de Itabaiana. A jovem deixou o interior para prosseguir os estudos na cidade de Aracaju. Na capital estudou no Atheneu Sergipense ${ }^{2}$ o ensino secundário entre os anos de 1935 e 1941 deixando essa "Casa de Educação Literária" para ingressar na primeira turma da graduação em Geografia História na Faculdade de Filosofia da Bahia.

Ainda como aluna do ensino superior ingressou como catedrática de Geografia Geral no Atheneu Sergipense, dali em diante assumiu diferentes postos de direção, publicou dezenas de artigos na imprensa local, participou de diferentes congressos com apresentação de trabalhos científicos e, sobretudo, ensinou e escreveu acerca de diferentes facetas da

\footnotetext{
2 Segundo Alves (2005), ao longo dos anos, o Atheneu Sergipense recebeu variadas denominações: Atheneu Sergipense (1870), Lyceu Secundário de Sergipe (1881), Escola Normal de Dois Graus (1882), Atheneu Sergipense (1890), Atheneu Pedro II (1925), Atheneu Sergipense (1938), Colégio de Sergipe (1942), Colégio Estadual de Sergipe (1943), Colégio Estadual Atheneu Sergipense (1970), e atualmente Centro de Excelência Colégio Atheneu Sergipense (desde 2003). Ao longo da tese, utilizarei a denominação Atheneu Sergipense, com exceção de quando se tratar de transcrição de fontes, na qual utilizarei o termo presente no documento. O Atheneu Sergipense foi criado em 1870, sendo a primeira escola de ensino secundário de Aracaju, ainda em funcionamento na aurora do século XXI, essa "Casa de Educação Literária" constituiu-se como a principal instituição de ensino secundário de Sergipe ao longo do final dos oitocentos e a primeira metade do século XX. A respeito dos diferentes traços da história do Atheneu Sergipense ver Alves (2005).
} 
História de Sergipe e do Brasil. Thetis Nunes possui a mais vasta obra sobre o passado sergipano, inclusive com uma síntese da História da Educação sergipana da colônia a república, além de um variado número de escritos sobre intelectuais, entre outras temáticas abordadas pela pesquisadora.

Diante da vastidão que envolve sua vida, o presente trabalho busca analisar os "itinerários" de Maria Thetis Nunes na sua vida escolar no recorte temporal de 1935 a 1941, período em que foi aluna do Atheneu Sergipense. O estudo dos "itinerários" ocorreu por meio da análise das origens do seu despertar intelectual e político nas instituições educacionais que frequentou e os mestres que foram registrados nas suas memórias. De acordo com o que escreveu Jean-François Sirinelli (2003):

[...] em todo caso, é possível e necessário fazer sua arqueologia [das estruturas de sociabilidade], inventariando as solidariedades de origem, por exemplo de idade ou de estudos, que constituem muitas vezes a base de 'redes' de intelectuais adultos. É lógico, sobretudo no caso dos acadêmicos, remontar a seus jovens anos escolares e universitários, numa idade em que as influências se exercem sobre um terreno móvel e em que uma abordagem retrospectiva permite reencontrar as origens do despertar intelectual e político (SIRINELLI, 2003, p. 249-250, grifos meus).

A proposta não consiste em fazer uma genealogia como adverte Sirinelli, mas uma arqueologia, na qual investigo como a vivência estudantil e os seus professores, colegas e escolas, contribuíram para conformar sua condição de intelectual. Jean-François Sirinelli (1998, 2003, 2006) ensina que a história dos intelectuais não é uma história autônoma, nem fechada sobre si, pelo contrário, é aberta e localizada no cruzamento das histórias política, social e cultural. Para o referido autor, o intelectual precisa ser estudado a partir de sua atuação tanto no âmbito político como cultural ou da produção do conhecimento. O teórico francês acentua que o meio intelectual constitui "um pequeno mundo estreito", no qual, "os laços se atam" em torno da redação de uma revista ou de um conselho editorial (SIRINELLI, 2003, p. 248). 
Entendo que as instituições educacionais também se configuram como um lugar no qual "os laços se atam" a depender da "sensibilidade ideológica ou cultural comum e de afinidades mais difusas”. Diante desse prisma, a análise dos itinerários permite visualizar como tais laços se conformaram ao longo do tempo e os espaços frequentados por essa jovem estudante de uma escola que abrigava, principalmente, um seleto grupo de pessoas que detinham certo poderio econômico e social em Sergipe.

O conceito de "itinerário" advém do mesmo autor, que trata dos "itinerários políticos” como aqueles que "[...] deveriam permitir desenhar mapas mais precisos dos grandes eixos de engajamento dos intelectuais" (SIRINELLI, 2003, p. 245). Utilizo o conceito de itinerários de acordo com o seguinte entendimento dos itinéraires:

Ces itinéraires individuels ou collectifs devraient donc permettre, par superposition, de faire apparaître les parcours types de l'engagement et aussi, en arrêtant le déroulement chronologique à une époque donnée, d'établir de véritables coupes datées de la societé intellectuelle. A travers deux dimensinons, seraient ainsi facilités le passage du portulan à la carte et celui de la radiographie au scanner, et disparaîtraient peu à peu les terrae incongnitae qui recouvrent encore largement, pour l'instant, les atlas dont l'historien dispose l'étude des intellectuels3 (SIRINELLI, 1986, p. 102).

A investigação dos itinerários de Maria Thetis Nunes possibilita compreender o percurso de uma jovem brasileira no seu processo de escolarização e engajamento em movimentos estudantis na primeira metade do século XX. Assim, as "terras desconhecidas”, no tocante à história dessa intelectual, são desbravadas de forma que explicito o modo como, por meio dos itinerários, pode-se compreender a mudança do "portulano

\footnotetext{
3 Tradução livre: "Estes itinerários individuais ou coletivos devem, portanto, permitir, por sobreposição, mostrar os tipos de percursos de engajamento e também, convencionando a sequência cronológica de um determinado momento ao estabelecer verdadeiros recortes de uma dada sociedade intelectual. Através de duas dimensões seria assim facilitada a passagem do portulano ao mapa, e da radiografia ao scanner, e desapareceriam pouco a pouco as terrae incongnitae (terras desconhecidas) que recobrem ainda amplamente, por enquanto, os atlas cujo historiador dispõe o estudo dos intelectuais".
} 
ao mapa" da mesma forma que "da radiografia ao scanner" no trato com os "criadores" e "mediadores culturais" (SIRINELLI, 2003).

Desse modo, faz-se necessário problematizar os itinerários da vida de Thetis Nunes, não como agente inerte situado em um tempo e um espaço e movido pelas circunstâncias de sua época, mas um ser com vontades, medos e expectativas que, diante de escolhas efetuadas ao longo de diferentes momentos de sua vida, construiu paulatinamente uma história, dentro de uma série de outras opções, ou não, que se apresentavam naquele momento.

Thetis Nunes, com onze anos de idade, deixou a cidade de Itabaiana, no interior de Sergipe, onde cursou o primário, a fim de prosseguir seus estudos na capital sergipana. Sua professora primária chamava-se Izabel Esteves de Freitas, renomada docente da cidade natal de Thetis. No discurso de posse na Academia Sergipana de Letras, Thetis Nunes faz referência a sua primeira professora e aos tempos de estudante em Itabaiana:

No magistério encontrei, a plena realização do meu ideal de vida. Professora eu sou desde os bancos ginasianos; mesmo acidentalmente ocupando outros cargos, nunca me afastei da sala de aula. Vocação despertada na infância numa singela escola pública isolada, pelo exemplo de uma professora admirável, a quem presto a minha homenagem: Izabel Esteves de Freitas. Ela acreditou na menina irrequieta e encantada pelos livros, e me estimulou a abrir caminhos além do horizonte, que me parecia intransponível, marcado pela serra de Itabaiana e suas ramificações e a seguir sempre em frente, sem esmorecimento para que os sonhos se tornassem vida (NUNES, 1990, p. 90, grifos meus).

As memórias de Thetis Nunes acerca do início da vida estudantil estão interligadas à sua atuação como professora; neste momento, que pode ser considerado um dos mais marcantes na vida de um intelectual sergipano no século XX: a posse na ASL, a itabaianense apresenta fragmentos dos seus itinerários perpassados por recordações distantes e nomes que contribuíram para sua conformação na carreira, ou mesmo que necessita citar para creditar uma origem do seu "despertar intelectual". Izabel Esteves estava nas memórias de Thetis no rol das pessoas que a 
incentivou a "abrir caminhos além dos horizontes" apresentados naquele momento. Contudo, não foram só os incentivos daquela professora, como também um conjunto de fatores familiares, sociais e econômicos que fizeram com que Thetis Nunes transpusesse a serra de Itabaiana para que "os sonhos se tornassem vida".

Dona Izabel, como ficou conhecida, é retratada por Carvalho (1973) como uma das fundadoras do jornal O Porvir. Em 1937, “[...] a professora Isabel Esteves de Freitas fundou O PORVIR. A princípio uma folha manuscrita, do próprio punho da mestra que copiava as melhores composições dos alunos e enviava o jornal depois para a Secretaria de Educação em Aracaju”. Esse é um fragmento da vida da mulher que, ao lado da mãe e da avó de Thetis, forneceu os primeiros rudimentos de educação à jovem itabaianense.

A mudança de toda a família para a capital do Estado, em 1935, proporcionou à Thetis Nunes a possibilidade de frequentar os bancos da Escola Normal Rui Barbosa. Possibilidade logo cerceada por conta da idade mínima para o ingresso naquela escola; dessa forma, foi orientada pela professora Leonor Telles de Menezes a prestar o exame de admissão no Atheneu Sergipense.

Conforme a Reforma Francisco Campos (BRASIL, 1931), no terceiro capítulo, há a abordagem à "admissão ao curso secundário": no artigo 24, consta que o candidato à primeira série do curso ginasial deveria realizar o exame de admissão, o qual "constará de provas escritas, uma de português, (redação e ditado) e outras de aritmética (cálculo elementar), e de provas orais sobre elementos dessas disciplinas e mais sobre rudimentos de Geografia, História do Brasil e Ciências Naturais”. Indica também que o candidato a exame de admissão deveria provar, por certidão do registro civil, ter a idade de 11 anos ou que a completará até 30 de junho do ano em que requerer a inscrição e apresentar a vacinação antivariólica e o pagamento da taxa de inscrição.

O Exame de Admissão de Maria Thetis Nunes ao Atheneu Sergipense foi realizado em 02 de março de 1935, obtendo as seguintes notas: Português: escrita 85 e oral 70, com a média final 77; Aritmética: prova escrita 70 e oral 90, com média final 80; Geografia 90; História do Bra- 


\section{Revista de História e \\ Historiografia da Educação}

sil: 90 e Ciências Naturais: 8o, com uma média geral de 83 pontos. (CERTIFICADOS DE EXAMES DE ADMISSÃO (1934-1946) - CEMAS).

Com um olhar atento, as cadeiras frequentadas por Maria Thetis Nunes no curso fundamental, na década de 1930, foi possível construir o seguinte quadro com cadeiras, professores e notas de Thetis Nunes:

Quadro 1 - Itinerários de Maria Thetis Nunes como discente do curso fundamental do Atheneu Sergipense (1935-1939). Fonte: Quadro elaborado pelo autor com base no Livro de Atas de Exames, cadernetas escolares e o Livro dos Funcionários localizados no CEMAS, além do material localizado no "Fundo Maria Thetis Nunes" no IHGSE e das informações colhidas no trabalho de Oliveira (2015). OBS: - - Docente não identificado.

\begin{tabular}{|c|c|c|c|c|}
\hline SÉRIE & ANO & CADEIRAS & PROFESSOR & $\begin{array}{l}\text { MÉDIA } \\
\text { ANUAL }\end{array}$ \\
\hline \multirow[t]{7}{*}{$1^{\mathrm{a}}$} & \multirow[t]{7}{*}{1935} & Português & Padre Avelar Brandão & 60 \\
\hline & & Francês & --------------------------- & 78 \\
\hline & & $\begin{array}{l}\text { História da Civili- } \\
\text { zação }\end{array}$ & Arthur Fortes & 77 \\
\hline & & Matemática & Gentil Tavares & 67 \\
\hline & & Geografia & Fraga Lima & 70 \\
\hline & & $\begin{array}{l}\text { Ciências Físicas e } \\
\text { Naturais }\end{array}$ & Augusto Cesar Leite & 54 \\
\hline & & Desenho & Joaquim Vieira Sobral & 82 \\
\hline \multirow[t]{8}{*}{$2^{a}$} & \multirow[t]{8}{*}{1936} & Português & Mario Miranda Vilas Bôas & 56 \\
\hline & & Francês & Padre Claudio Diniz de Faro Dantas & 77 \\
\hline & & Inglês & Felte Bezerra & 70 \\
\hline & & $\begin{array}{l}\text { História da Civili- } \\
\text { zação }\end{array}$ & Arthur Fortes & 86 \\
\hline & & Geografia & José de Magalhães Carneiro & 82 \\
\hline & & Matemática & Abdias Bezerra & 80 \\
\hline & & $\begin{array}{l}\text { Ciências Físicas e } \\
\text { Naturais }\end{array}$ & Augusto Cesar Leite & 54 \\
\hline & & Desenho & Joaquim Vieira Sobral & 72 \\
\hline \multirow[t]{10}{*}{$3^{\mathrm{a}}$} & \multirow[t]{10}{*}{1937} & Português & Mario Miranda Vilas Bôas & 85 \\
\hline & & Francês & -------------------------- & 77 \\
\hline & & Inglês & ------------------------- & 92 \\
\hline & & $\begin{array}{l}\text { História da Civili- } \\
\text { zação }\end{array}$ & Arthur Fortes & 86 \\
\hline & & Geografia & -------------------------- & 91 \\
\hline & & Matemática & ------------------------ & 77 \\
\hline & & Física & José Rollemberg Leite & 54 \\
\hline & & Química & José Andrade Carvalho & 62 \\
\hline & & História Natural & Oscar Baptista do Nascimento & 70 \\
\hline & & Desenho & -------------------------- & 87 \\
\hline $4^{\mathrm{a}}$ & 1938 & Português & Mario Miranda Vilas Bôas & 61 \\
\hline
\end{tabular}




\section{Revista de História e Historiografia da Educação}

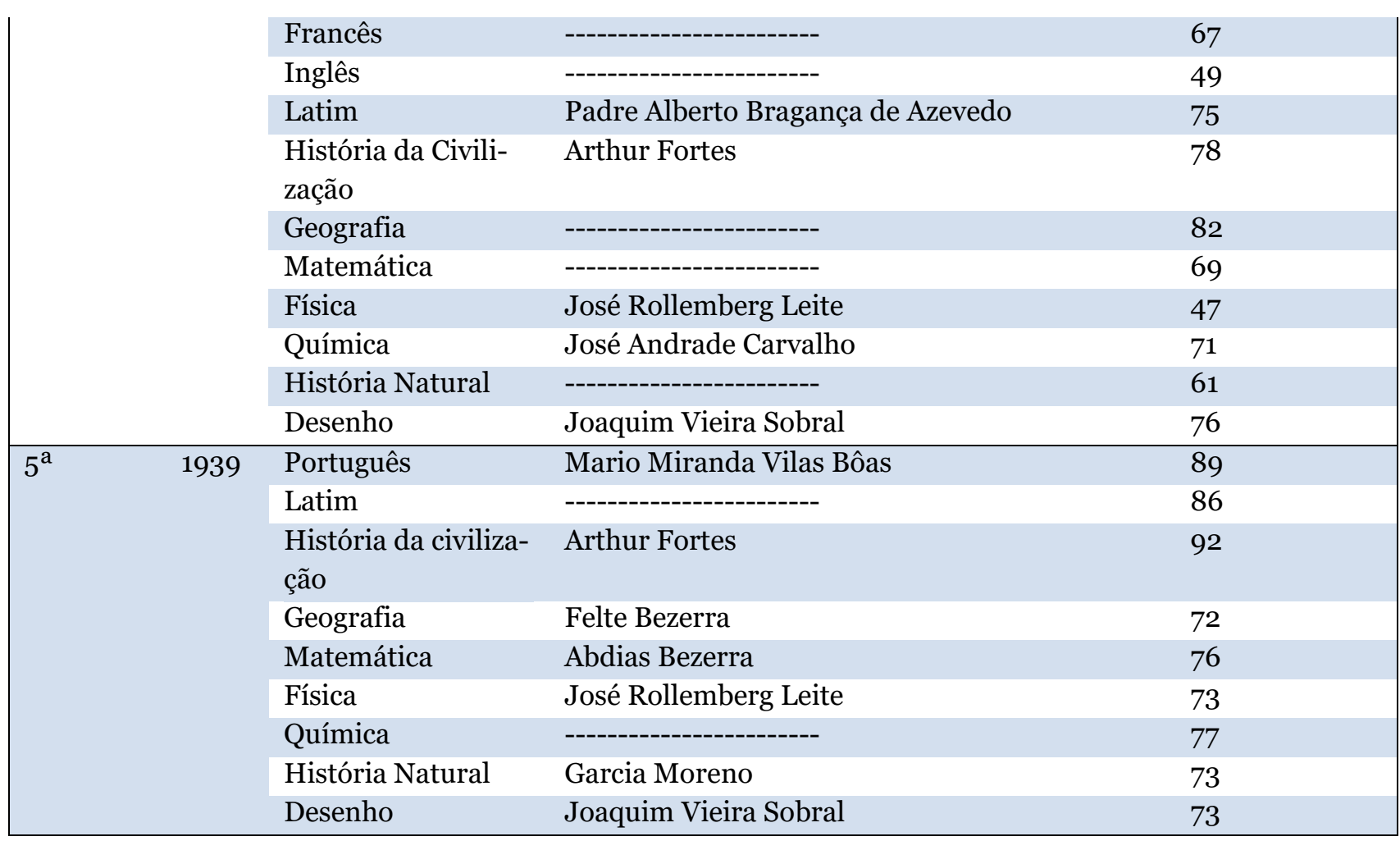

O quadro, que retrata o curso fundamental4 como parte da formação do ensino secundário de Maria Thetis Nunes se apresenta como um grande quebra cabeça: fornece pistas do percurso formativo da jovem Thetis, que chegou ao Atheneu Sergipense ainda criança, deixando-o sete anos depois rumo ao ensino superior. Pelo quadro, nota-se que o desempenho da aluna nas diferentes disciplinas é variável. Ao longo do período de 1935 a 1939, a disciplina de História da Civilização foi uma das que Thetis alcançou as maiores notas em comparação ao conjunto dos dados coletados.

4“Art. $3^{\circ}$ Constituirão o curso fundamental as matérias abaixo indicadas, distribuídas em cinco anos, de acordo com a seguinte seriação: $1^{\mathrm{a}}$ série: Português - Francês - História da civilização - Geografia - Matemática - Ciências físicas e naturais - Desenho Música (canto orfeônico). $2^{\mathrm{a}}$ série: Português - Francês - Inglês - História da civilização - Geografia - Matemática - Ciências físicas e naturais - Desenho - Música (canto orfeônico). $3^{\mathrm{a}}$ série: Português - Francês - Inglês - História da civilização - Geografia Matemática - Física - Química - História natural - Desenho - Música (canto orfeônico). $4^{\mathrm{a}}$ série: Português - Francês - Inglês - Latim - Alemão (facultativo) - História da civilização - Geografia - Matemática - Física - Química - História Natural - Desenho. $5^{\text {a }}$ série: Português - Latim - Alemão (facultativo) - História da civilização - Geografia - Matemática - Física - Química - História natural - Desenho” (BRASIL, 1931). 
Pela análise do quadro, é possível perceber as cadeiras que compunham o ensino secundário humanístico do Atheneu Sergipense no contexto da Reforma de Francisco Campos; mas também quais as áreas de conhecimento possuíam presença nos diferentes anos do curso, repetindo-se ao longo de todo o curso fundamental.

Ao falar sobre as disciplinas escolares, Chervel afirma que: "O ensino das matérias ensinadas simultaneamente no mesmo estabelecimento de ensino constitui em cada época uma rede disciplinar que não deixa de exercer uma influência mais ou menos forte sobre cada um de seus constituintes" (CHERVEL, 1990, p. 214). E assim, ressalta-se a vinculação do que é ensinado em cada disciplina e o cidadão que se almeja formar. As finalidades que uma disciplina agrega estão atreladas ao meio social da época que as instituiu; dessa forma, a repetição de uma disciplina em várias séries ou mesmo sua carga horária também dizem respeito aos objetivos da educação escolarizada.

Analisando o quadro de cadeiras estudadas por Maria Thetis Nunes ao longo do curso complementar do secundário à luz da Reforma Francisco Campos, observo alguns dos elementos apontados por Dallabrida e Souza (2014), entre os quais, o espaço das "Ciências Físicas e Naturais" nos dois primeiros anos do curso Fundamental e "Física - Química - História Natural" nos demais anos. O aumento de tais disciplinas na formação do estudante secundarista denota "[...] uma quebra no predomínio do eixo literário, indicando uma perspectiva burguesa" (DALLABRIDA; SOUZA, 2014, p. 14). Outro ponto relevante concerne à:

[...] significativa a presença do ensino das ciências sociais, físicas e naturais. História da Civilização, Geografia e Matemática são disciplinas estudadas em todas as séries do curso e o mesmo ocorre com Desenho. O estudo das ciências físicas e naturais adquire pela primeira vez no ensino secundário, uma distribuição mais equânime e coerente que se inicia nas duas primeiras séries, desdobrando-se nas séries seguintes em Física, Química e História Natural (SOUZA, 2008, p. 54).

As disciplinas com melhor avaliação de desempenho durante o curso fundamental se constituíam justamente em História e Geografia. Elas ultrapassaram os oitenta pontos em três, dos cinco anos que estudou tais 
cadeiras. Outra área do conhecimento em destaque foi a Literatura, existente somente no $5^{\mathrm{O}}$ ano, após quatro anos de estudos de Português. Vale ressaltar que a presença da disciplina de Português, em todos os anos do curso, também foi uma inovação da Reforma de 1931. Desse modo, é possível perceber a articulação entre o currículo secundarista à sociedade da época de modo que: "Essa ênfase à língua materna, articulada com as disciplinas História, Geografia e Canto Orfeônico, procurava tonificar o nacionalismo, que se adensava cada vez mais após a Revolução de 1930. O tom científico e nacionalista, portanto, estava transversalizado nesse currículo, sendo seriado em várias 'disciplinas-saber" (DALLABRIDA; SOUZA, 2014, p. 14).

Com relação às notas obtidas pela aluna, em 1935, ano de sua chegada no Atheneu Sergipense e em Aracaju, constituiu-se como o momento de médias mais baixas de todo o curso, sendo que somente em Desenho ela conseguiu ultrapassar os oitenta pontos; nessa mesma cadeira, seu rendimento caiu nos anos seguintes, exceto em 1937, como também foi a média mais baixa dentre as disciplinas presentes no seu exame vestibular na Faculdade de Filosofia da Bahia em 1942.

No tocante às avaliações, Chervel (1990) declara: “[...] permanece o fato de que as provas finalmente destinadas ao exame ou ao concurso concentram em torno delas a atenção e o interesse do mestre e dos alunos, influindo mesmo, no total sobre as classes anteriores" (CHERVEL, 1990, p. 207). Dessa forma, as avaliações são alguns dos constituintes fundamentais de uma disciplina, pois, por meio delas, pode-se aferir se determinadas finalidades foram alcançadas.

Dentro dessa perspectiva, tomando como prisma as avaliações, é possível afirmar que Thetis Nunes atendia às expectativas dentro do conjunto de saberes fundamentais na realidade do governo varguista estabelecidos na reforma de Francisco Campos, mantendo uma média nas disciplinas de História e Geografia. Em contraposição, as novas disciplinas inseridas no currículo secundarista, a saber, Física e História Natural, constituíram as menores médias gerais da itabaianense.

Dos professores de Thetis Nunes no Atheneu Sergipense, ela destaca em suas memórias Abdias Bezerra, Arthur Fortes, Mário Vilas Boas, 
Florentino Menezes e o diretor Joaquim Vieira Sobral. Conforme o mesmo Livro de Funcionários (CEMAS), Abdias Bezerra ingressou na Congregação por concurso para a cadeira de Francês em 26 de maio de 1909, mas como ocorria constantemente no Atheneu Sergipense, os professores tinham suas cátedras alteradas e, depois de lecionar Desenho e Português, a partir de 1915, passou à cátedra de Geometria e Trigonometria e, no ano seguinte, Aritmética e Álgebra. Após 1930, com a Reforma Francisco Campos e a união das "Matemáticas", lecionou Matemática no Atheneu Sergipense. Relativo a Arthur Fortes, o discurso de Thetis Nunes, diante da colocação da fotografia do mestre na sala da Congregação do Atheneu Sergipense, retrata em certa medida, a afinidade.

Um dia, neste desafiar contínuo de gerações, por esta casa, símbolo das tradições gloriosas da inteligência sergipana, os jovens que olhando este retrato que ora inauguramos, perguntarão: Quem foi ele? Os seus mestres lhe responderão: foi um poeta, foi um professor e foi, principalmente, um homem livre. O seu nome é Arthur Fortes (NUNES, 1945, não p.).

O professor e poeta foi constantemente relembrado por Thetis, ao longo da sua vida, mais de sessenta anos depois, em entrevista concedida no ano de 2007, Thetis Nunes reafirmou a influência de Arthur Fortes nas suas escolhas, inclusive, pelo magistério. Possivelmente, tais vínculos também tenham colaborado para a volta de Thetis como professora do Atheneu Sergipense, não na cátedra de História Geral do seu professor, a qual concorreu em concurso, mas na cadeira de Geografia Geral.

As atas da Congregação do Atheneu Sergipense fornecem algumas pistas do que a aluna Thetis Nunes estudava nas suas aulas. Conforme Ata de 18 de março de 1937, ano em que Thetis cursava a terceira série, o livro de Francês seria o curso completo de Gastão Ruch, para Alemão, que aparece como uma disciplina optativa, indicam-se as obras: Leituras Alemãs de Th. Beck e A. Chignard; para Matemática, qualquer compêndio de Cecil Thiré e Munhoz Meader; para Geografia, seria adotado Aroldo Azevedo e G. Lima. No caso de História Geral, como o catedrático Artur Fortes não estava presente naquela reunião, foi indicado pelo professor de História do Brasil, Costa Filho, o compêndio de Joaquim Silva que 
tinha sido adotado no ano anterior. As demais cadeiras continuaram com os mesmos compêndios de 1936 (LIVRO DE ATAS DA CONGREGAÇÃO DO ATHENEU SERGIPENSE (1916-1939) - CEMAS).

Com relação ao seu professor Mário Vilas Boas, motivada com a notícia do seu falecimento, Thetis escreveu:

\begin{abstract}
A ele devo os conhecimentos básicos da língua pátria adquirido nos dois anos e meio que fui sua aluna. Era um didata perfeito, sem nunca ter estudado didática ciência bem desconhecida, entre nós naquela época. Suas aulas ricas em conhecimento linguístico mantinha a classe alerta e interessada dadas que eram com métodos e numa dicção perfeita que nos encantava. [...] a palavra eloquente do professor nos transmitia através da leitura da página a ser estudada que primeiro era feita por êle. Alencar, Machado de Assis, Rui Coelho e Melo, Herculano Camões, passaram sem esforço a ser nossos conhecidos. [...] As palavras aqui são da aluna que não esqueceu o mestre e suas aulas [...] (NUNES, 1968, p. 2).
\end{abstract}

O cotidiano das aulas no ensino secundário de Thetis Nunes aponta para aspectos da História da Educação brasileira daquele período. Autores lidos em sala, os métodos de ensino, os conteúdos estudados podem ser vislumbrados em uma matéria com tom de saudosismo, tendo em vista o falecimento do homenageado. Além disso, Thetis faz questão de ressaltar que os escritos são da aluna do Atheneu e não da professora universitária que já ocupava vários cargos em Sergipe no final da década de 1960.

Dentro do espaço do Atheneu Sergipense, Thetis Nunes começou a construir o seu nome se diferenciando dos demais alunos, pelas notas angariadas, participação nas aulas e amizades com os professores. Todos esses elementos contribuíram para o seu retorno como professora interina pouco tempo após terminar o curso complementar e alguns anos mais tarde, como catedrática de Geografia Geral.

Certamente no direcionamento das aulas de História, Fortes, o "poeta da rosa vermelha", deixou marcas indeléveis na formação da jovem Thetis. Em viagem à Áustria, em 1977, ou seja, três décadas depois das aulas com Arthur Fortes, Thetis escreveu: 
Andando por esses faustosos palácios, vendo desfilarem reis e príncipes através de retratos pintados por grandes mestres, me vão pulando do fundo da memória as aulas de história do meu grande professor Artur Fortes no velho Ateneu da Rua da Frente. Mas são elas avivadas quando o guia nos indica o local quando Napoleão triunfante se deteve ao entrar em Viena, após a fuga da família imperial, ou onde se reuniu o congresso que em, 1815, reformulou o mapa político da Europa depois de Waterloo (NUNES, 1977, p. 3).

Thetis Nunes tinha o hábito de publicar constantemente nos jornais sergipanos relatos das viagens realizadas. Nesse caso, a memória revela lembranças das aulas de Arthur Fortes que, ao serem comparadas com as anotações presentes no caderno da aluna do ensino secundário, reitera a ideia da permanência de elementos da vida escolar na vida dos sujeitos ao passarem pela escola. As aulas de Fortes aparecem constantemente nos relatos da Thetis Nunes historiadora, talvez mais do que um professor, Fortes simbolizava na sua memória um ponto de referência para o início da sua trajetória.

Para Nely Santos: "Indiscutivelmente, o jornalista, poeta e parlamentar Arthur Fortes foi o professor de maior influência de sua vida estudantil" (SANTOS, 1999, p. 92). As marcas deixadas pelo professor Arthur Fortes nos seus alunos podem ser visualizadas em outros depoimentos de discentes que estudaram no Atheneu Sergipense na década de 1930.

Além dessas facetas da discente Thetis Nunes, observa-se também seu envolvimento na política estudantil daquele estabelecimento de ensino. Rodrigues (2015) pontua que as alunas Neusa Nascimento e Maria Thetis Nunes participaram como sócias e oradoras do Grêmio Literário Clodomir Silva, o que é perceptível no seu discurso na Inauguração do Centro Estudantil, em 1938:

Platão afirmava: 'um dia, uma hora, um momento de heroísmo vale mais que um século de prudência vulgar ou de virtude trivial'. E foi com os olhos dirigidos para estas palavras do imortal filósofo grego que ousei-me dirigir a tão ilustre auditório a fim de desempenhar a missão que me confiaram: representar nesta solenidade a mocidade feminina de minha terra. Aceitei esta missão com entusiasmo porque via o apoio de minhas colegas esta idéia 
dos jovens estudantes demonstrando que já não é a mulher antiga, enclausurada nas alcovas sombrias, completamente alheia ás letras, á civilização e sim a mulher instruída que dia a dia vai revelando sua inteligência, sua inclinação, as artes, a literatura (NUNES, 1938, s/p).

Esse fragmento inicial do discurso de Thetis Nunes, na condição de aluna do quarto ano do curso fundamental do Atheneu Sergipense, aponta elementos do pensamento da jovem estudante defensora dos direitos das mulheres e representante das alunas daquela instituição de ensino no ato de inauguração do Centro Estudantil. Tal discurso é seguido por referências à Júlia Lopes de Almeida, Victor Hugo, Aristóteles e Sócrates. Além disso, expressa seu pensamento através de frases como: "A educação de um povo é um dos urgentes e maiores problemas"; e na conclusão do parágrafo final afirma: "O progresso é um Tiradentes dando seu sangue em prol da liberdade da Terra de Santa Cruz”.

Um discurso como o citado, proferido em um auditório repleto de estudantes e entre eles algumas mulheres, possivelmente, contribuiu para que o nome de Thetis Nunes ganhasse relevo no meio estudantil, sendo não mais a menina de Itabaiana que chegou à cidade grande, mas também construindo "redes" por meio de laços de afetividade e ideológicos, dialogando com os escritos de Sirinelli (2003).

Faz-se necessário ressaltar ainda que o discurso proferido pela aluna Thetis Nunes é datado de 1938, um ano após o chamado Golpe do Estado Novo de Getúlio Vargas, ou seja, a liberdade nos diferentes cantos do país era vigiada, mas no Atheneu Sergipense, a itabaianense continuou a estudar e, em 1939, concluiu o seu curso fundamental. Em suas próprias palavras, Thetis Nunes assim descreve o período de estudante daquela "Casa de Educação Literária", sob a direção de Joaquim Vieira Sobral:

Lá chegando criança, cursaria os cinco anos ginasiais e os dois complementares, dentro do esquema da Reforma Francisco Campos. [...] Grande parte dessa vivência ocorreu sob a direção de Joaquim Sobral, que se iniciou quando eu ainda cursava a primeira série ginasial. [...]. Foi ele um precursor da assistência ao estudante pobre, numa época que o jovem desprovido de re- 
cursos não contava com qualquer ajuda dos poderes públicos para estudar (NUNES, 1980, p. 2).

O que se pode entender por "estudante pobre"? Talvez os elogios que Thetis Nunes efetuou ao professor de Desenho estejam atrelados ao apoio fornecido a ela e a outros sergipanos que, não possuidores de vasto capital econômico, como muitos dos seus colegas de classe, sentaram nos bancos do velho Atheneu e dali seguiram para diferentes profissões de comando. Possivelmente, Thetis Nunes precisou do apoio de Joaquim Sobral na fase de adaptação à escola, ou mesmo para poder se integrar ao ambiente novo que surgia na vida da interiorana no universo de muitos professores e exigências próprias do secundário da época. Os escritos sobre a direção de Joaquim Sobral também auxiliam no entendimento dos itinerários da vida estudantil de Thetis Nunes, Cabral Machado, Silvério Leite e Bonifácio Fortes que estiveram naquela instituição como alunos nesse período e de Felte Bezerra, companheiro de Congregação do "percursor na assistência do estudante pobre".

Assim, Thetis Nunes e mais outros poucos concludentes do curso continuaram os preparativos para o ingresso no ensino superior nos chamados cursos complementares. No Atheneu Sergipense, Thetis Nunes foi aluna daqueles que depois foram seus colegas de profissão: Abdias Bezerra, Felte Bezerra, Gentil Tavares, José Augusto da Rocha Lima, José Rollemberg Leite, Gonçalo Rollemberg Leite, Mario Vilas Boas, Arthur Fortes entre outros. Este último marcou profundamente sua formação como professora e historiadora.

No Atheneu Sergipense, Maria Thetis Nunes estudou durante sete anos, concluiu o ginásio em 1939 e o curso pré-jurídico em 1941. Segundo a Reforma Francisco Campos no seu Art. 50: "Para os candidatos à matrícula no curso jurídico são disciplinas obrigatórias: $1^{\mathrm{a}}$ série: Latim - Literatura - História da civilização - Noções de Economia e Estatística - Biologia geral - Psicologia e Lógica. $2^{\mathrm{a}}$ série Latim - Literatura - Geografia - Higiene - Sociologia - História da Filosofia”. Em entrevista a Jucá Melo (2006), Thetis Nunes credita sua formação a vários docentes, entre eles alguns professores do Instituto Superior de Estudos Brasileiros, como: 
Álvaro Vieira Pinto, Guerreiro Ramos, Inácio Rangel, Celso Furtado e Nelson Werneck Sodré e outros do Atheneu Sergipense.

[...] tive professores maravilhosos, como Arthur Fortes, Gonçalo Rollemberg Leite, que foi o meu professor de Literatura por dois anos e que abriu o meu caminho para conhecer a literatura do Brasil e principalmente de Sergipe. Manoel Bomfim, eu só conheci graças a Gonçalo e depois me foi útil quando no ISEB tive que desenvolver um trabalho com conotações nacionalistas; como sou ligada a Sergipe e queria fazer um trabalho relativo a Sergipe aí me lembrei de Manoel Bomfim, que o professor Gonçalo tanto falava e fui estudar este Manoel Bomfim (NUNES, 2006 apud MELO, 2006, p. 55).

Gonçalo Rollemberg, seu professor de Literatura do curso préjurídico, reitera o papel do docente na formação dos alunos. No caso de Thetis, a pesquisa sobre Manoel Bonfim remete a uma lembrança das aulas de Literatura com Gonçalo. Do Atheneu Sergipense, seguiu para a Faculdade de Filosofia da Bahia para ser aluna da primeira turma do curso de Geografia e História.

A trajetória estudantil no Atheneu Sergipense de Maria Thetis Nunes evidencia que sua vinculação com a História estava para além da formação superior ou ingresso na docência, mas perpassou sua vida escolar. Assim, as fontes escrutinadas ao longo do capítulo corroboram com as assertivas de Bontempi Júnior de que:

[...] cada sujeito é único e suas experiências são irreplicáveis. Ao final deste cruzamento de autobiografias, porém, em que circunstâncias e significados muito semelhantes foram vividos e percebidos quase simultaneamente por sujeitos que não se conheciam, toma vulto o que nos envolve, o que respiramos e que, no entanto, não podemos ver. Surge a imagem do que nos aproxima e do que faz os singulares serem tão familiares. A presença da instituição escolar em nossa vida social, como experiência prática e como representação, torna-nos alunos, cria para nós, os colegas, põe-nos diante professores-paradigma, responde de algum modo às expectativas e esperanças de nossos pais, de nossas famílias. Quando damos o salto para a docência, é a essas experiências que procuramos dar sentido, pois são elas que compõem os traços do auto-retrato que desejamos ser vistos e considerado belo, que nos definem como indivíduo único e irredutível e simultaneamente como membro de uma coletividade 
que compartilha valores e experiências. Passamos pela escola, como é trivial, mas em momentos como esse é que percebemos como ela passou para dentro de nós (BONTEMPI JUNIOR, 2010, p. 177, grifos meus).

Na presente pesquisa, mostro como a vivência na escola "passou para dentro" dessa intelectual brasileira. "Professores-paradigma" são creditados como influenciadores dos caminhos percorridos pela jovem estudante secundarista. Memórias construídas tempos depois quando se propôs a pensar a vida de uma longa distância, mas que possuíam um embasamento na história vivida nas salas de aula e outros espaços de práticas educativas.

Tais práticas escolares dos seus professores, somadas ao universo cultural no qual Thetis Nunes esteve imersa, contando com contribuições do ambiente familiar, com as amizades dentro e fora da sala de aula, as viagens e as mudanças para estudar constituem-se como elementos que reiteram o significado da "instituição escolar na nossa vida social", assim como reafirmam a importância dos estudos dos itinerários formativos para a compreensão do intelectual, bem como da História da Educação brasileira na primeira metade do século XX.

\section{Referências}

ALVES, Eva Maria Siqueira. O Atheneu Sergipense: uma Casa de Educação Literária examinada segundo os Planos de Estudos (1870/1908). Tese (Doutorado em Educação). Programa de Estudos Pós-Graduados em Educação: História, Política e Sociedade, PUC/SP, 2005. 318 p.

BONTEMPI JÚNIOR, Bruno. Os significados da vida estudantil e da escola nos memoriais dos candidatos à docência na FEUSP (1988-2005). In: MORAES, Dislane Zerbinatti; LUGLI, Rosario Silvana Genta. Docência, pesquisa e aprendizagem: (auto)biografias como espaços de formação/investigação. São Paulo: Cultura Acadêmica, 2010. p. 165-178.

BRASIL. Decreto 19.890 de 18 de abril de 1931 (conhecida por Reforma Francisco Campos). Disponível em: http://www.histedbr.fe.unicamp.br/ navegando/fontes_escritas/5_Gov_Vargas/decreto\%2019.890-\%20193 
1\%20reforma\%2ofrancisco\%20campos.htm. Acesso em 23 de outubro de 2014.

CARVALHO, Vladimir de Souza. Santas Almas de Itabaiana Grande. Itabaiana: Editora Serrano, 1973.

CEMAS, Centro de Educação e Memória do Atheneu Sergipense. Certificados de Exames de Admissão (1934-1946). Ref. 428FASSo6. Cx. 107.

CEMAS, Centro de Educação e Memória do Atheneu Sergipense. Livro com o quadro de funcionários docentes, disciplinas e séries (1926-1953). 480FASSo9.

CEMAS, Centro de Educação e Memória do Atheneu Sergipense. Livro de Atas da Congregação do Atheneu Sergipense (1916-1939). Ref. 496FASSO1.

CHERVEL, André. História das disciplinas escolares: reflexões sobre um campo de pesquisa. In: Teoria \& Educação, Porto Alegre/RS, n. 2, 1990, p. 177-229.

DALLABRIDA, Norberto; SOUZA, Rosa Fátima de. O todo poderoso império do meio: transformações do ensino secundário entre a Reforma Francisco Campos e a primeira LDBEN (à guisa de apresentação). In: DALLABRIDA, Norberto; SOUZA, Rosa Fátima de (Orgs.). Entre o ginásio de elite e o colégio popular: estudos sobre o ensino secundário no Brasil (1931-1961). Uberlândia: EDUFU, 2014. p. 11-30.

MELO, Jucá Adriano Silva. Leituras de Maria Thetis Nunes. Monografia (Conclusão de Curso em História). Graduação em Licenciatura em História da Universidade Tiradentes (Unit). Aracaju/SE, 2006. 55 p.

NUNES, Maria Thetis. Discurso de Inauguração do Centro Estudantil de Sergipe. 21 de agosto de 1938. Aracaju/SE. Acervo particular da autora doado ao IHGSE (FMT. S5. CX 520. Doc. 001).

NUNES, Maria Thetis. O prof. Artur Fortes soube viver o seu momento. In: Correio de Aracaju. Aracaju/SE. 28 de julho de 1945.

NUNES, Maria Thetis. Dom Mario: o Professor. In: A Cruzada. Aracaju/SE. 16 de março de 1968. p. 2. Hemeroteca do IHGSE.

NUNES, Maria Thetis. Viena, onde a História e a Arte se confundem. In: Gazeta de Sergipe. Aracaju/SE. 14 de setembro de 1977. p. 3. Hemeroteca do IHGSE.

NUNES, Maria Thetis. Joaquim Sobral, o Pioneiro da Assistência ao Estudante Pobre. In: Gazeta de Sergipe. Aracaju/SE. 10 de outubro de 1980. p. 3. Hemeroteca do IHGSE.

NUNES, Maria Thetis. Discurso de Posse na Academia Sergipana de Letras na cadeira $\mathrm{n}^{0}$ 39. In: Revista da Academia Sergipana de Letras. Aracaju, $n^{0}$ 30, 1990. p. 81-94 
NUNES, Maria Thetis. Professora da FCFS. Entrevista concedida ao autor em 15 de agosto de 2007. Aracaju/SE.

RODRIGUES, Simone Paixão. Com a palavra, os alunos: associativismo discente no Grêmio Literário Clodomir Silva (1934-1956). 2015. Tese (Doutorado em Educação). Programa de Pós-Graduação em Educação da Universidade Federal de Sergipe, São Cristóvão - SE, 2015. 337 p.

SANTOS, Maria Nely. Professora Thétis: uma vida. Aracaju: Gráfica Pontual, 1999.

SIRINELLI, Jean-François. Le hasard ou la necessité: une histoire en chantier: L'histoire des intelectuells. Vingtième Siècle: Revue d'Histoire. Vol. 9, $\mathrm{n}^{0}$ 1. jan./maio 1986. p. 97-108.

SIRINELLI, Jean-François. As elites culturais. In: RIUX, Jean Pierre e SIRINELLI, Jean-François. Para uma história cultural. Lisboa: Estampa, 1998. p. 259-279.

SIRINELLI, Jean-François. Os intelectuais. In: RÉMOND, René (Org.). Por uma história política. 2. ed. Tradução Dora Rocha. Rio de Janeiro: Editora FGV, 2003. p. 231-269.

SIRINELLI, Jean-François. A Geração. In: FERREIRA, Marieta de Moraes; AMADO, Janaína (Orgs.). 8. ed. Usos e Abusos da História Oral. Rio de Janeiro: Editora FGV, 2006. p. 167-182.

SOUZA, Rosa Fátima de. História da organização do trabalho escolar e do currículo no século $X X$ (ensino primário e secundário no Brasil). São Paulo: Cortez, 2008. (Biblioteca básica de História da Educação Brasileira, v. 2). Aprovado em 17 de abril de 2016. 